\title{
On the Mechanical Friction Losses Occurring in Automotive Differential Gearboxes
}

\author{
Grégory Antoni \\ Haute Ecole d'Ingénierie et de Gestion du Canton de Vaud, Institut COMATEC, Route de Cheseaux 1, \\ 1401 Yverdon-les-Bains, Switzerland
}

Correspondence should be addressed to Grégory Antoni; antoni.gregory@yahoo.fr

Received 13 August 2013; Accepted 19 October 2013; Published 19 January 2014

Academic Editors: C. W. Leung, F. Liu, and S. J. Rothberg

Copyright (C) 2014 Grégory Antoni. This is an open access article distributed under the Creative Commons Attribution License, which permits unrestricted use, distribution, and reproduction in any medium, provided the original work is properly cited.

\begin{abstract}
In the automobile industry, the mechanical losses resulting from friction are largely responsible for various kinds of surface damage, such as the scuffing occurring in some mechanical assemblies. These scuffing processes seem to be due to a local loss of lubrication between certain mechanical elements of the same assembly, leading to a sharp increase in the friction, which can lead to a surface and volume damage in some of them, and even can cause, in the worst case, the whole destruction of the mechanical system if it has continued to operate. Predicting and checking the occurrence of this kind of undesirable phenomena, especially in some principal systems of the vehicle, represents nowadays, a crucial challenge in terms of automobile reliability and safety. This study focuses on the mechanical friction losses liable to occur in differential automobile gearboxes, which can lead in the long term to the scuffing of these mechanical systems. The friction losses involved were modeled, using a simple analytical approach, which is presented and discussed.
\end{abstract}

\section{Introduction}

Although the automobile industry has contributed significantly during the last few years to increasing the $\mathrm{CO}_{2}$ levels polluting the atmosphere, the introduction of a Carbon Tax has been inciting car manufacturers to reduce this pollution. In line with this more environmentally friendly approach, automobile manufacturers are now attempting to decrease the mechanical friction losses occurring between some vehicle parts-causing both an increase in fuel consumption and levels of carbon dioxide emissions-while maintaining their company's competitiveness on the market. In practice, these friction losses are frequently associated with surface damage of several kinds such as scuffing [1-6] which is also known as galling [7] or seizure [8-10]. Scuffing is an extreme form of adhesive wear which occurs when two mechanical parts adhere locally to each other and a material transfer takes place from the one surface to the other during a sliding process, which in turn can result in the welding or binding of the entire mechanical system [11-14]. Although the physical causes of scuffing have not yet been clearly established, it is generally recognized that they are initiated when the lubricant film between two sliding parts is suddenly destroyed as the result of a sharp temperature increase due to the presence of heavy mechanical loads [15]. The most accurate and efficient methods of predicting scuffing processes are those based on estimating the thermal energy responsible for this damage in comparison with that produced under normal operating conditions $[16,17]$. The friction energy dissipated in the mechanical assemblies in question must therefore thus be assessed to define a criterion in order to predict the occurrence of the resulting scuffing effects $[16,17]$. The mechanical losses to which the differential gearboxes are subject, can lead to a surface and volume damage of one or more elements of this system, and causing, in the worst case, the blocking and the destruction of the system, if it remains in operation. In this study on the mechanical friction losses occurring in differential automobile gearboxes, an analytical model was developed (see Section 2) in order to determine the contribution of each mechanical component to the overall friction losses. In Section 3, the relative contribution of each of the constitutive components of the model and the effects of various parameters on the mechanical friction losses occurring in a differential gearbox are discussed. 

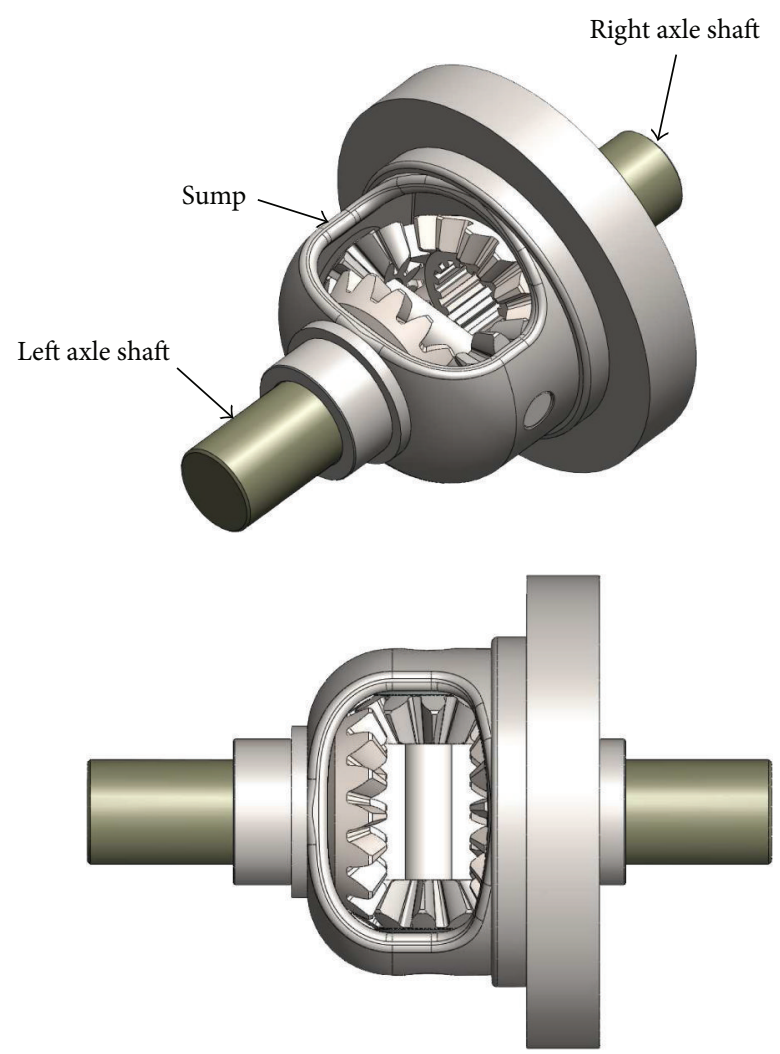

FIguRE 1: Differential gearbox (with its sump and the axle shafts).

\section{Analysis of the Mechanical Friction Losses Occurring in Differential Automobile Gearboxes: Constitutive Equations}

2.1. General Description. Generally speaking, a differential gearbox [18] (Figure 1) is a complex device involving gears which are connected to output shafts transmitting both rotation and torque forces. In the framework of motor vehicles, differential systems of this kind make it possible to deliver an equal or different speed to all the wheels, depending on whether the vehicle is taking a straight or curvilinear course: when the vehicle is starting to turn, the inner wheels must rotate more slowly than those in the outside because they have to cover a smaller distance during the same time span. Differential systems consist of four bevel gears (two "planetary" pinions and two "satellite" pinions), a satellite-carrier axis, and a plastic shell (Figure 2); all these components are enclosed in a nonsymmetric sump entrained by the differential ring gear, which is itself driven in a rotating manner by both the primary and secondary gearbox shafts, which are made to rotate by the engine of the vehicle. The two planetary bevel pinions connected to each axle shaft placed opposite each other are meshed by the two smaller satellite pinions (Figure 3). When the vehicle is moving straight ahead, the two planetary pinions rotate at the same speed (as does the axle shaft associated with each of the driven wheel) and the two satellite pinions are stationary relative to their axis; that is, the differential housing and these pinions rotate at the same speed as the ring gear. However, when the vehicle turns, the rotational speed of the wheel (and that of the corresponding planetary pinions) differs from that of the two satellite pinions, which start rotating around their axis in order to compensate for this difference.

2.2. Power and Yield Equations. The total gearbox yield, $\eta_{\mathrm{gb}}$, is obtained by dividing the sum of the output powers of each of the driven wheels by the gearbox's input power:

$$
\eta_{\mathrm{gb}}=\frac{P_{\mathrm{lw}}+P_{\mathrm{rw}}}{P_{\mathrm{en}}}=\frac{C_{\mathrm{lw}} \omega_{\mathrm{lw}}+C_{\mathrm{rw}} \omega_{\mathrm{rw}}}{C_{\mathrm{en}} \omega_{\mathrm{en}}},
$$

where $P_{i}, C_{i}$, and $\omega_{i}$ (with $i=(\mathrm{lw}, \mathrm{rw}, \mathrm{en})$ ) are powers, torques, and angular velocities associated with the left wheel, right wheel, and engine, respectively.

Upon introducing both the primary and secondary gearbox shaft yields, the ratio between the power of the differential ring gear and that of the engine is equal to the product of these shaft yields; that is,

$$
\eta_{\mathrm{ps}} \eta_{\mathrm{ss}}=\frac{P_{\mathrm{rg}}}{P_{\mathrm{en}}}=\frac{C_{\mathrm{rg}} \omega_{\mathrm{rg}}}{C_{\mathrm{en}} \omega_{\mathrm{en}}},
$$

where $\eta_{\mathrm{ps}}$ and $\eta_{\mathrm{ss}}$ denote the primary and secondary shaft yields, respectively, and $P_{\mathrm{rg}}, C_{\mathrm{rg}}$ and $\omega_{\mathrm{rg}}$ are the power, torque and angular velocity associated with the differential ring gear (drive gear), respectively.

On the other hand, the total gearbox yield can be written as the product of the primary and secondary shaft yields and the differential gearbox:

$$
\eta_{\mathrm{gb}}=\eta_{\mathrm{ps}} \eta_{\mathrm{ss}} \eta_{\mathrm{di}}
$$

After combining (1)-(3), the total differential gearbox yield, $\eta_{\mathrm{di}}$, can be obtained by dividing the sum of the output powers of each of the driven wheels by the input power:

$$
\eta_{\mathrm{di}}=\frac{P_{\mathrm{lw}}+P_{\mathrm{rw}}}{P_{\mathrm{rg}}}=\frac{C_{\mathrm{lw}} \omega_{\mathrm{lw}}+C_{\mathrm{rw}} \omega_{\mathrm{rw}}}{C_{\mathrm{rg}} \omega_{\mathrm{rg}}} .
$$

Since a differential gearbox can both transmit and distribute the differential ring gear power (the input power) to the output gears associated with each of the driven wheels, it follows that

$$
P_{\mathrm{rg}}=P_{\mathrm{lw}}+P_{\mathrm{rw}}+P_{\mathrm{ab}}
$$

where $P_{\mathrm{ab}}$ is the power absorbed in the differential gearbox due to the friction losses.

In the equations governing the angular velocities and the torques in the differential gearbox (Figure 4),

$$
\begin{gathered}
\omega_{\mathrm{lw}} R_{p}=\omega_{\mathrm{rg}} R_{p}-\omega_{s} R_{s}, \\
\omega_{\mathrm{rw}} R_{p}=\omega_{\mathrm{rg}} R_{p}+\omega_{s} R_{s}, \\
C_{\mathrm{rg}}=C_{\mathrm{lw}}+C_{\mathrm{rw}},
\end{gathered}
$$




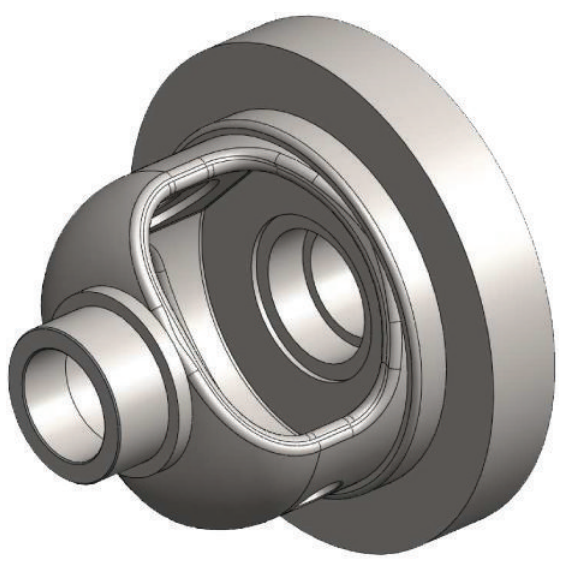

(a)

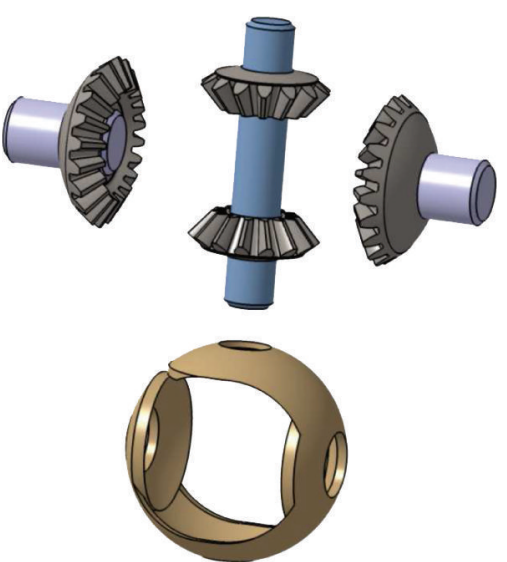

(b)

Figure 2: (a) Sump of a differential gearbox. (b) Various components of a differential mechanism.
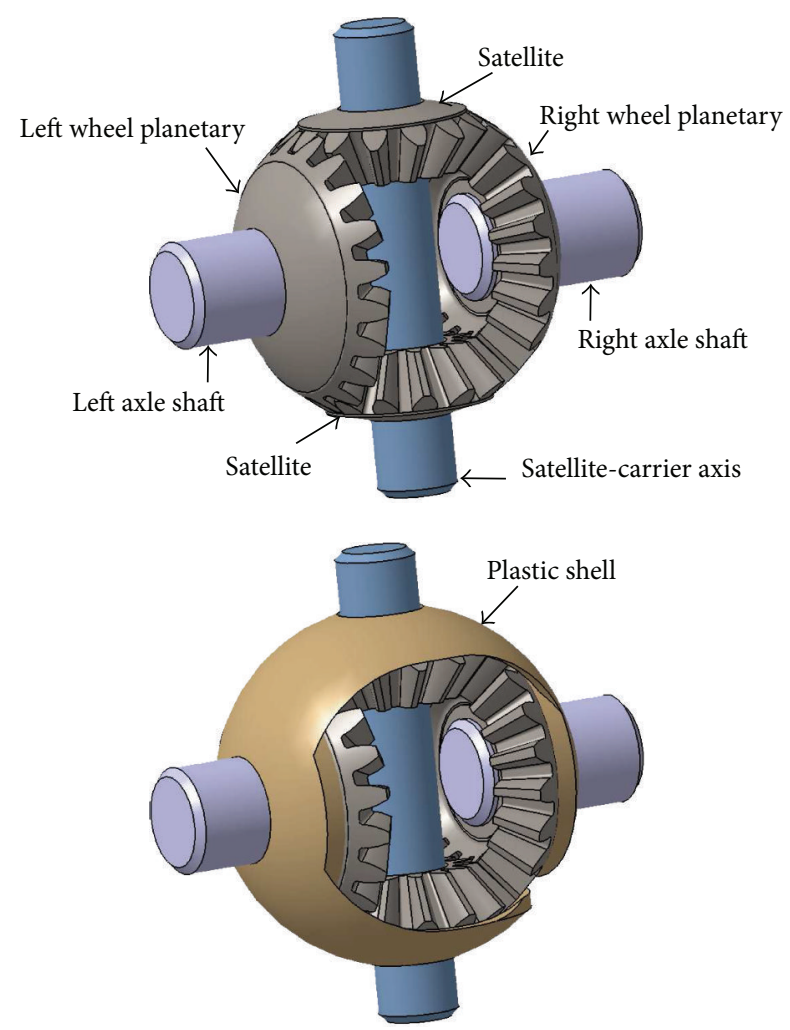

FIGURE 3: Components of a differential gearbox: two planetary bevel pinions, two satellite bevel pinions with their shaft and the plastic shell.

where $\omega_{s}$ denotes the angular velocity of satellite pinion and $R_{p}$ and $R_{s}$ are the pitch radii of planetary and satellite pinions, respectively.

Adding or subtracting (6a)-(6b), we obtain the classical relations:

$$
\omega_{\mathrm{rg}}=\frac{\omega_{\mathrm{lw}}+\omega_{\mathrm{rw}}}{2},
$$

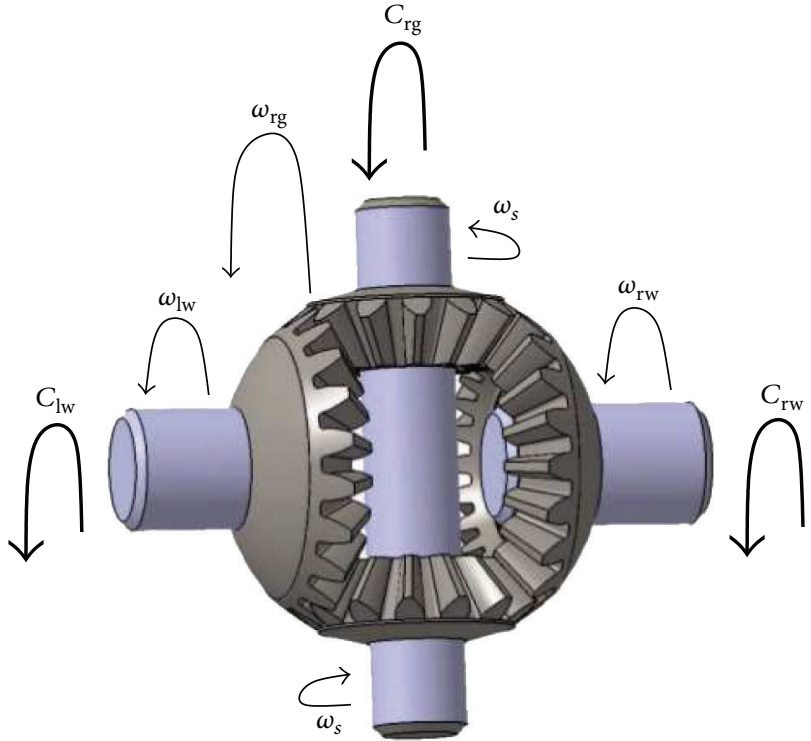

FIGURE 4: Angular velocities and torques in the differential gearbox.

$$
\omega_{s}=\frac{\omega_{\mathrm{rw}}-\omega_{\mathrm{lw}}}{2} \frac{R_{p}}{R_{s}} .
$$

Note that from now on, $\Delta \omega=\left|\omega_{\mathrm{lw}}-\omega_{\mathrm{rw}}\right| \geq 0$ and $\Delta C=\left|C_{\mathrm{rw}}-C_{\mathrm{lw}}\right| \geq 0$ will be used to denote the difference in the angular velocity and torque between the driven wheels, respectively (where $|\cdot|$ is the absolute-value function).

Combining (5) and (6a), (6b), and (7), the power absorbed in the differential can be written as

$$
P_{\mathrm{ab}}=\frac{1}{2} \Delta C \Delta \omega .
$$

Based on the above equations, the total differential gearbox yield is

$$
\eta_{\mathrm{di}}=1-\frac{P_{\mathrm{ab}}}{P_{\mathrm{rg}}}=1-\left(\frac{\Delta C \Delta \omega}{2 C_{\mathrm{rg}} \omega_{\mathrm{rg}}}\right) .
$$




\section{Comments}

(i) Under straight driving conditions, the angular velocities of two satellite pinions in relation to the satellite axis are zero $(\Delta \omega=0)$ and the speed of the driven wheels is equal to the angular velocity of the differential ring gear; that is, $\omega_{\mathrm{lw}}=\omega_{\mathrm{rw}}=\omega_{\mathrm{rg}}$.

(ii) In curvilinear driving situations, the angular velocity of two satellite pinions in relation to the satellitecarrier axis is no longer zero $(\Delta \omega>0)$ and the speeds of the driven wheels are no longer equal; that is, $\omega_{\mathrm{lw}}>$ $\omega_{\text {rw }}$ (right turn) or $\omega_{\mathrm{lw}}<\omega_{\mathrm{rw}}$ (left turn).

(iii) If one of the driven wheels undergoes slipping [18] —if it is the left (resp., right) wheel, $\omega_{\mathrm{lw}}=0$ (resp., $\omega_{\mathrm{rw}}=$ 0 ), that is, $\Delta \omega=2 \omega_{\mathrm{rg}}$-the differential gearbox yield reduces to $\eta_{\mathrm{di}}=1-\left(\Delta C / C_{\mathrm{rg}}\right)$.

2.3. Mechanical Losses: Friction Torques. The power absorbed in the differential gearbox is the sum of the power dissipated at the various contact points existing in the overall mechanism, which can be decomposed as follows:

$$
P_{\mathrm{ab}}=P_{\mathrm{sa} / \mathrm{pl}}+P_{\mathrm{ax} / \mathrm{sa}}+P_{\mathrm{sa} / \mathrm{sh}}+P_{\mathrm{pl} / \mathrm{sh}},
$$

where $P_{\mathrm{sa} / \mathrm{pl}}, P_{\mathrm{ax} / \mathrm{sa}}, P_{\mathrm{sa} / \mathrm{sh}}$, and $P_{\mathrm{pl} / \mathrm{sh}}$ correspond to the part of the power dissipated between the two satellite and planetary bevel pinions, the satellite pinion and the satellite-carrier axis, between the two bevel heads of the satellite pinions and the surrounding plastic shell, and the two bevel heads of the planetary pinions and the surrounding plastic shell (see Figure 3).

\subsubsection{Power Dissipated between Two Satellite Bevel Pinions} and Two Planetary Bevel Pinions. In order to account for the power dissipated between the two satellite bevel pinions and the two planetary bevel pinions in the differential mechanism (giving four meshing contacts), we introduce a yield, $\eta_{\mathrm{sa} / \mathrm{pl}}$ (denoting the power transmitted in the gear between satellite/planetary pinions) which can be written as follows:

$$
\eta_{\mathrm{sa} / \mathrm{pl}}=\frac{P_{\mathrm{rg}}-P_{\mathrm{sa} / \mathrm{pl}}}{P_{\mathrm{rg}}} H^{+}(\Delta \omega),
$$

where $P_{\mathrm{sa} / \mathrm{pl}}$ denotes the power dissipated between the two satellite/planetary contacts and $H^{+}(\cdot)$ is a Heaviside-like function (adapted in order to ensure that $H^{+}(x)=1$ when $x>0$ and $H(x)=0$ when $x \leq 0)$. Note that a yield $\eta_{\mathrm{sa} / \mathrm{pl}}$, with a nonzero value (i.e., $\eta_{\mathrm{sa} / \mathrm{pl}}>0$ ), occurs between the two satellite pinions and two planetary pinions only when the angular velocity differs between the driven wheels; that is, $\Delta \omega>0$.

Based on (12), we can therefore write

$$
P_{\mathrm{sa} / \mathrm{pl}}=\left(1-\eta_{\mathrm{sa} / \mathrm{pl}}\right) C_{\mathrm{rg}} \omega_{\mathrm{rg}} H^{+}(\Delta \omega) .
$$

2.3.2. Power Dissipated between the Satellite Bevel Pinion and Satellite-Carrier Axis. Neglecting the presence of an over-centre mechanism between the satellite pinion and satellite-carrier axis (Figure 5), the force exerted on the satellite-carrier axis, $F_{\text {ax }}$, upon the rotation of the differential ring gear $\left(\omega_{\text {rg }}\right)$ can be written as

$$
F_{\mathrm{ax}}=\frac{C_{\mathrm{rg}}}{2 R_{p}} .
$$

In (14), the point of application of the force, $F_{\mathrm{ax}}$, is assumed to take the same contact path as both the left and right meshing gears (Figure 7).

Adopting a Coulomb-type friction law, the friction torque applied to the satellite-carrier axis, $C_{\mathrm{ax} / \mathrm{sa}}^{f}$ is

$$
C_{\mathrm{ax} / \mathrm{sa}}^{f}=\mu_{\mathrm{ax} / \mathrm{sa}} F_{\mathrm{ax}} \frac{d_{\mathrm{ax}}}{2},
$$

where $\mu_{\mathrm{ax} / \mathrm{sa}}$ denotes the friction coefficient (which is constant) between the satellite pinion and the satellite-carrier axis and $d_{\mathrm{ax}}$ is the axis diameter (Figure 6).

Combining (14) and (15), the power dissipated between these two assembly components reads

$$
P_{\mathrm{ax} / \mathrm{sa}}=2 C_{\mathrm{ax} / \mathrm{sa}}^{f} \omega_{s}=\mu_{\mathrm{ax} / \mathrm{sa}} \frac{C_{\mathrm{rg}}}{4} \frac{d_{\mathrm{ax}}}{R_{\mathrm{s}}} \Delta \omega .
$$

2.3.3. Power Dissipated between the Satellite Bevel Pinions and the Plastic Shell. The power dissipated between the two bevel satellite pinions and the surrounding plastic shell, $P_{\mathrm{sa} / \mathrm{sh}}$, can be written as

$$
P_{\mathrm{sa} / \mathrm{sh}}=2 C_{\mathrm{sa} / \mathrm{sh}}^{f} \omega_{s}=C_{\mathrm{sa} / \mathrm{sh}}^{f} \frac{R_{p}}{R_{s}} \Delta \omega,
$$

where $C_{\mathrm{sa} / \mathrm{sh}}^{f}$ denotes the friction torque applied to the satellite bevel pinion. Note that the friction torque, $C_{\mathrm{sa} / \mathrm{sh}}^{f}$, is assumed here to be identical on the two satellite pinions.

In order to write the equations giving the equilibrium of each satellite pinion, which is meshed with the two planetary pinions associated with the driven wheels and in contact with the satellite-carrier axis as well as with the plastic shell, we use the Fundamental Principle of Statics:

$$
\left\{T_{\mathrm{lw} \rightarrow S}\right\}_{M}+\left\{T_{\mathrm{rw} \rightarrow S}\right\}_{M}+\left\{T_{\mathrm{ax} \rightarrow S}\right\}_{M}+\left\{T_{\mathrm{sh} \rightarrow S}\right\}_{M}=\{0\},
$$

where $\left\{T_{i \rightarrow S}\right\}_{M}$ denotes the transmittable force torsor of solid $i$ (and $i=(\mathrm{lw}, \mathrm{rw}, \mathrm{ax}, \mathrm{sh})$ associated with the planetary pinions of the left and right wheels, the satellite-carrier axis, and the plastic shell, resp.) exerted on solid $S$ (the satellite pinion) at point $M$ (see [15]).

Looking only at the equilibrium of the resulting force of each torsor in the direction $(x, y, z)$ (see Figure 7), (18) writes

$$
\left\{\begin{array}{l}
F_{\mathrm{lw}}^{t} \\
F_{\mathrm{lw}}^{r} \\
F_{\mathrm{lw}}^{a}
\end{array}+\left\{\begin{array}{l}
F_{\mathrm{rw}}^{t} \\
-F_{\mathrm{rw}}^{r} \\
F_{\mathrm{rw}}^{a}
\end{array}+\left\{\begin{array}{l}
-F_{\mathrm{ax}} \\
0 \\
0
\end{array}+\left\{\begin{array}{l}
0 \\
0 \\
-X_{\mathrm{sa}}
\end{array}=\left\{\begin{array}{l}
0 \\
0 \\
0
\end{array}\right.\right.\right.\right.\right.
$$

$\Longleftrightarrow\left\{\begin{array}{l}F_{\mathrm{lw}}^{t}+F_{\mathrm{rw}}^{t}=F_{\mathrm{ax}} \\ F_{\mathrm{lw}}^{r}=F_{\mathrm{rw}}^{r} \\ \left(F_{\mathrm{lw}}^{t}+F_{\mathrm{rw}}^{t}\right) \tan \alpha \sin \delta=X_{\mathrm{sa}}\end{array}\right.$ 

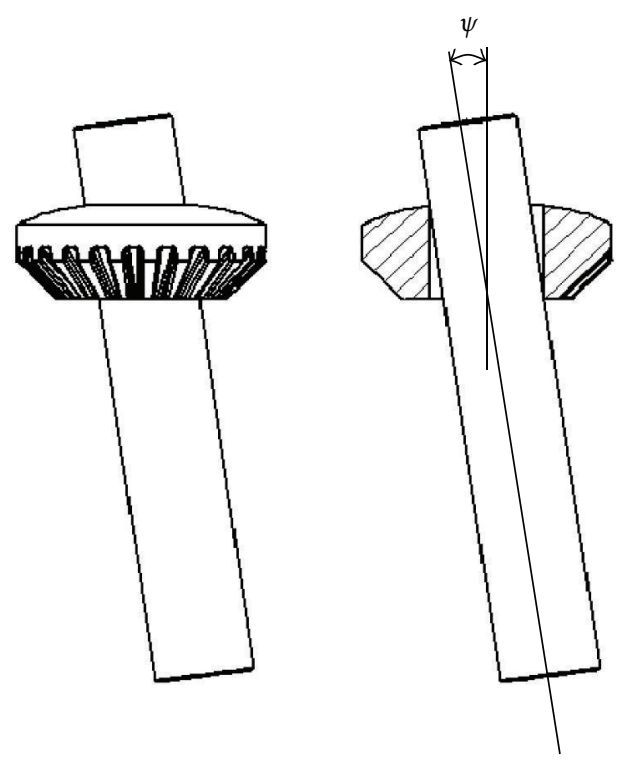

FIGURE 5: Over-centre mechanism between the satellite pinion and satellite-carrier axis; $\psi$ denotes the angular eccentricity.

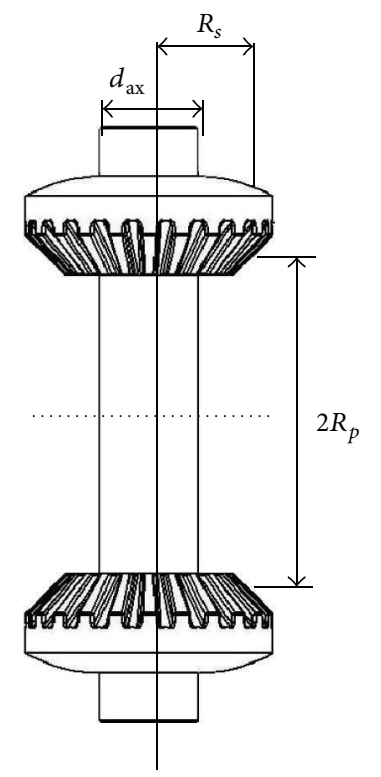

Figure 6: Satellite bevel pinions and satellite-carrier axis.

where $F_{j}^{t}, F_{j}^{r}$, and $F_{j}^{a}$ (with $j=1 w, r w$ ) are the tangential, radial, and axial forces of $j$-planetary pinions (associated with the left and right wheels, Figure 7; see [19]), respectively, $X_{\mathrm{sa}}$ is the resulting force applied to the satellite pinion generated by the plastic shell, $\delta$ is the half-angle pitch radius of the satellite pinion (see Figure $8(\mathrm{a})$ ), and $\alpha$ is the pressure angle between the satellite and planetary pinions, which is assumed here to be identical between the satellite/planetary meshing gears (see Figure 8(b)).

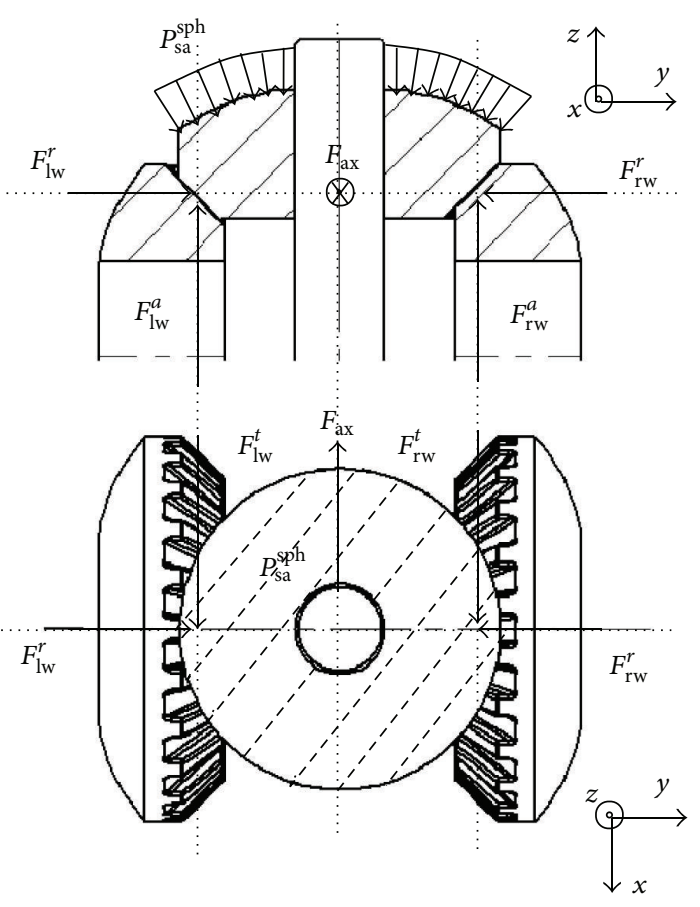

FIGURE 7: Forces applied to a satellite pinion.

The pressure applied to the head surface of the satellite pinion $P_{\mathrm{sa}}^{\mathrm{sph}}$ (its spherical part, see Figure 9) due to the resulting force, $X_{\mathrm{sa}}$ (in line with (20)) matches the relationship (see [15]):

$$
X_{\mathrm{sa}}=\int_{0}^{2 \pi} \int_{\delta_{0}}^{\delta_{1}} P_{\mathrm{sa}}^{\mathrm{sph}}(\theta, \phi) R_{\mathrm{sa}}^{2} \cos \theta \sin \theta d \theta d \phi,
$$

where $\delta_{1}$ and $\delta_{0}$ are the angles defining the spherical part of the head-satellite pinion and $R_{\mathrm{sa}}$ is the radius of the inner sphere of the plastic shell (where the contact with the head surface of the satellite pinion and the plastic shell occurs).

The expression for the friction torque $C_{\mathrm{sa} / \mathrm{sh}}^{f}$ applied to the head surface of the satellite pinion can be written (see [17]) as

$$
\begin{aligned}
C_{\mathrm{sa} / \mathrm{sh}}^{f} & =\int_{0}^{2 \pi} \int_{\delta_{0}}^{\delta_{1}} \tau_{\mathrm{sa}}^{\mathrm{sph}}(\theta, \phi) R_{\mathrm{sa}}^{3} \sin \theta d \theta d \phi \\
& =\int_{0}^{2 \pi} \int_{\delta_{0}}^{\delta_{1}} \mu_{\mathrm{sa} / \mathrm{sh}} P_{\mathrm{sa}}^{\mathrm{sph}}(\theta, \phi) R_{\mathrm{sa}}^{3} \sin \theta d \theta d \phi,
\end{aligned}
$$

where $\tau_{\mathrm{sa}}^{\mathrm{sph}}(\theta, \phi)=\mu_{\mathrm{sa} / \mathrm{sh}} P_{\mathrm{sa}}^{\mathrm{sph}}(\theta, \phi)$ denotes the shear stress exerted on the head surface of the satellite pinion since a Coulomb-type friction law is adopted (see Figure 9) and $\mu_{\mathrm{sa} / \mathrm{sh}}$ is the coefficient of friction (which is constant) between the satellite pinion and the plastic shell. 


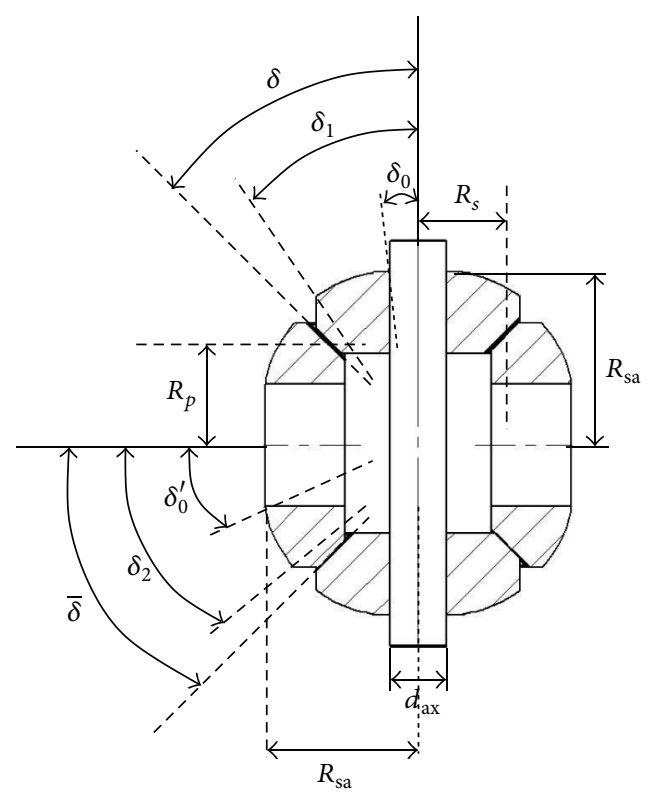

(a)

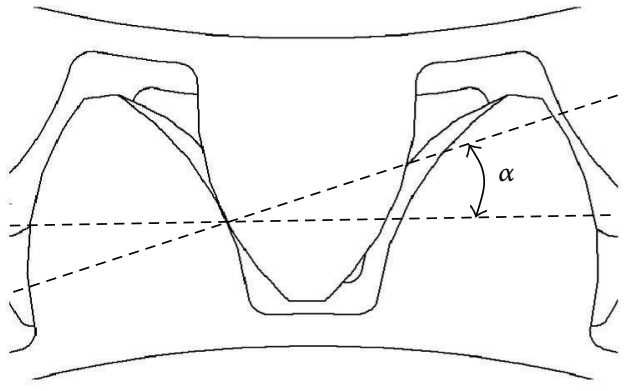

(b)

FIGURE 8: Geometry of a differential gearbox.
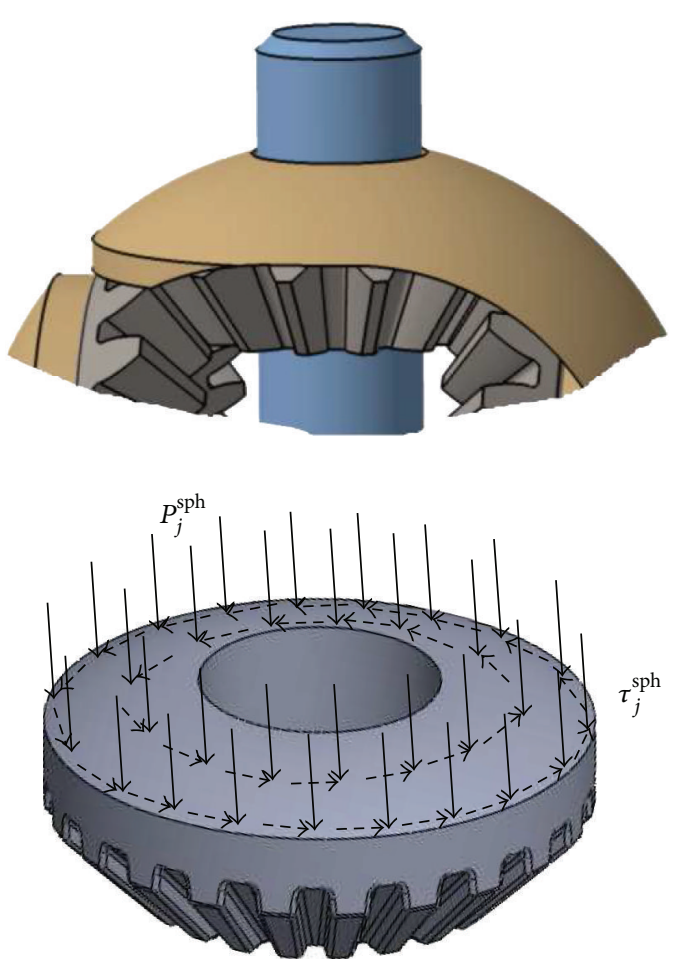

Figure 9: Pressure $P_{j}^{\text {sph }}$ (solid arrow) and shear $\tau_{j}^{\text {sph }}$ (dashed arrow) fields on a head-pinion $j$ (with $j=(\mathrm{sa}, \mathrm{pl})$ ) caused by the plastic shell.

Combining (14) and (20)-(22) and assuming that, in a first approximation, the pressure field exerted on the head-satellite pinion is uniform (i.e., $\left.P_{\mathrm{sa}}^{\mathrm{sph}}(\theta, \phi)=P_{\mathrm{sa}}^{\mathrm{sph}}\right),(21)$ and (22) reduce to

$$
\begin{aligned}
X_{\mathrm{sa}}= & 2 \pi R_{\mathrm{sa}}^{2} P_{\mathrm{sa}}^{\mathrm{sph}}\left(\frac{\cos \left(2 \delta_{0}\right)-\cos \left(2 \delta_{1}\right)}{4}\right), \\
C_{\mathrm{sa} / \mathrm{sh}}^{f}= & \mu_{\mathrm{sa} / \mathrm{sh}} R_{\mathrm{sa}} \frac{C_{\mathrm{rg}}}{2 R_{p}} \tan \alpha \sin \delta \\
& \times\left(\frac{\cos \left(\delta_{1}+\delta_{0}\right) \sin \left(\delta_{1}-\delta_{0}\right)-\left(\delta_{1}-\delta_{0}\right)}{\sin \left(\delta_{0}+\delta_{1}\right) \sin \left(\delta_{0}-\delta_{1}\right)}\right) .
\end{aligned}
$$

2.3.4. Power Dissipated between the Planetary Bevel Pinions and the Plastic Shell. The power dissipated between the two planetary pinions and the plastic shell, $P_{\mathrm{pl} / \mathrm{sh}}$, can be written as

$$
P_{\mathrm{pl} / \mathrm{sh}}=C_{\mathrm{pl} / \mathrm{sh}}^{f(\mathrm{~s})} \omega_{\mathrm{lw}}^{\mathrm{rs}}+C_{\mathrm{pl} / \mathrm{sh}}^{f(\mathrm{rw})} \omega_{\mathrm{rw}}^{\mathrm{rs}}
$$

where $C_{\mathrm{pl} / \mathrm{sh}}^{f(i)}$ are the frictional torque between the planetary $i$ pinion $(i=(\mathrm{lw}, \mathrm{rw})$ refers to the left wheel (lw) and the right wheel $(\mathrm{rw}))$ and the plastic shell, and $\omega_{i}^{\mathrm{rs}}=\Delta \omega / 2$ denotes the relative speed of the $i$-pinion in relation to the sump differential.

Assuming that $C_{\mathrm{pl} / \mathrm{sh}}^{f(\mathrm{lw})} \cong C_{\mathrm{pl} / \mathrm{sh}}^{f(\mathrm{rw})}=C_{\mathrm{pl} / \mathrm{sh}}^{f}$, (24) reads

$$
P_{\mathrm{pl} / \mathrm{sh}}=C_{\mathrm{pl} / \mathrm{sh}}^{f} \Delta \omega .
$$

Using the same procedure as above, namely, meshing each of the planetary pinions with two satellite pinions, which 
means that the resulting force applied to the head-planetary pinion by the plastic shell, $X_{\mathrm{pl}}$, is

$$
X_{\mathrm{pl}}=F_{\mathrm{ax}} \tan \alpha \sin \bar{\delta}
$$

where $\bar{\delta}$ is the half-angle pitch radius of the planetary pinion (see Figure 8(a)). Note that given the particular geometry of the mechanism, the sum of the half-angle pitch radii of the planetary and satellite pinions satisfies $\delta+\bar{\delta}=\pi / 2$, and we therefore obtain the following relationship: $\sin \bar{\delta}=\cos \delta$.

The expressions for both the resulting force, $X_{\mathrm{pl}}$, and the friction torque, $C_{\mathrm{pl} / \mathrm{sh}}^{f}$, applied to the head-satellite pinion are:

$$
\begin{gathered}
X_{\mathrm{pl}}=\int_{0}^{2 \pi} \int_{\delta_{0}^{\prime}}^{\delta_{2}} P_{\mathrm{pl}}^{\mathrm{sph}}(\theta, \phi) R_{\mathrm{sa}}^{2} \cos \theta \sin \theta d \theta d \phi, \\
C_{\mathrm{pl} / \mathrm{sh}}^{f}=\int_{0}^{2 \pi} \int_{\delta_{0}^{\prime}}^{\delta_{2}} \tau_{\mathrm{pl}}^{\mathrm{sph}}(\theta, \phi) R_{\mathrm{sa}}^{3} \sin \theta d \theta d \phi,
\end{gathered}
$$

where $\tau_{\mathrm{pl}}^{\mathrm{sph}}(\theta, \phi)=\mu_{\mathrm{pl} / \mathrm{sh}} P_{\mathrm{pl}}^{\mathrm{sph}}(\theta, \phi)$ denotes the shear stress exerted on the outer surface of the planetary pinion with a Coulomb-type friction law (Figure 9), $\mu_{\mathrm{pl} / \mathrm{sh}}$ is the coefficient of friction (which is constant) between the satellite pinion and the plastic shell, $P_{\mathrm{pl}}^{\mathrm{sph}}$ is the pressure applied to the head surface of the planetary pinion, and $\delta_{2}$ and $\delta_{0}^{\prime}$ are the angles defining the spherical portion of the head-planetary pinion.

It is again assumed here that in a first approximation, the pressure field, $P_{\mathrm{pl}}^{\mathrm{sph}}$, exerted on the head-planetary pinion is uniform (i.e., $(\theta, \phi)$-independent), and (27) reduce to

$$
\begin{aligned}
X_{\mathrm{pl}}= & 2 \pi R_{\mathrm{sa}}^{2} P_{\mathrm{pl}}^{\mathrm{sph}}\left(\frac{\cos \left(2 \delta_{0}^{\prime}\right)-\cos \left(2 \delta_{2}\right)}{4}\right), \\
C_{\mathrm{pl} / \mathrm{sh}}^{f}= & \mu_{\mathrm{pl} / \mathrm{sh}} R_{\mathrm{sa}} \frac{C_{\mathrm{rg}}}{2 R_{p}} \tan \alpha \cos \delta \\
& \times\left(\frac{\cos \left(\delta_{2}+\delta_{0}^{\prime}\right) \sin \left(\delta_{2}-\delta_{0}^{\prime}\right)-\left(\delta_{2}-\delta_{0}^{\prime}\right)}{\sin \left(\delta_{0}^{\prime}+\delta_{2}\right) \sin \left(\delta_{0}^{\prime}-\delta_{2}\right)}\right) .
\end{aligned}
$$

2.3.5. Total Power Dissipated in the Differential Gearbox. Based on the above constitutive equations, the total power dissipated in the differential gearbox can be written as follows:

$$
\begin{aligned}
P_{\mathrm{ab}} & =P_{\mathrm{sa} / \mathrm{pl}}+P_{\mathrm{ax} / \mathrm{sa}}+P_{\mathrm{sa} / \mathrm{sh}}+P_{\mathrm{pl} / \mathrm{sh}} \\
& =\left(1-\eta_{\mathrm{sa} / \mathrm{pl}}\right) C_{\mathrm{rg}} \omega_{\mathrm{rg}} H^{+}(\Delta \omega)+\mu_{\mathrm{ax} / \mathrm{sa}} \frac{C_{\mathrm{rg}}}{4} \frac{d_{\mathrm{ax}}}{R_{s}} \Delta \omega
\end{aligned}
$$

$$
\begin{aligned}
& +\mu_{\mathrm{sa} / \mathrm{sh}} R_{\mathrm{sa}} \frac{C_{\mathrm{rg}}}{2 R_{\mathrm{s}}} \tan \alpha \sin \delta \\
& \times\left(\frac{\cos \left(\delta_{1}+\delta_{0}\right) \sin \left(\delta_{1}-\delta_{0}\right)-\left(\delta_{1}-\delta_{0}\right)}{\sin \left(\delta_{0}+\delta_{1}\right) \sin \left(\delta_{0}-\delta_{1}\right)}\right) \Delta \omega \\
& +\mu_{\mathrm{pl} / \mathrm{sh}} R_{\mathrm{sa}} \frac{C_{\mathrm{rg}}}{2 R_{p}} \tan \alpha \cos \delta \\
& \times\left(\frac{\cos \left(\delta_{2}+\delta_{0}^{\prime}\right) \sin \left(\delta_{2}-\delta_{0}^{\prime}\right)-\left(\delta_{2}-\delta_{0}^{\prime}\right)}{\sin \left(\delta_{0}^{\prime}+\delta_{2}\right) \sin \left(\delta_{0}^{\prime}-\delta_{2}\right)}\right) \Delta \omega .
\end{aligned}
$$

Using (10) and (29) and assuming that in a first approximation, $\mu_{\mathrm{sa} / \mathrm{sh}}=\mu_{\mathrm{pl} / \mathrm{sh}}=\mu_{\mathrm{sh}}$ (where $\mu_{\mathrm{sh}}$ denotes the coefficient of friction between each of the pinions in contact with the plastic shell), the total differential gearbox yield can be written as follows:

$$
\begin{aligned}
& \eta_{\mathrm{di}}=1-\sum_{i} l_{i} \\
& =1-[\underbrace{\frac{P_{\mathrm{sa} / \mathrm{pl}}}{P_{\mathrm{rg}}}}_{=l_{\mathrm{sa} / \mathrm{pl}}}+\underbrace{\frac{P_{\mathrm{ax} / \mathrm{sa}}}{P_{\mathrm{rg}}}}_{=l_{\mathrm{ax} / \mathrm{sa}}}+\underbrace{\frac{P_{\mathrm{sa} / \mathrm{sh}}}{P_{\mathrm{rg}}}}_{=l_{\mathrm{sa} / \mathrm{sh}}}+\underbrace{\frac{P_{\mathrm{pl} / \mathrm{sh}}}{P_{\mathrm{rg}}}}_{=l_{\mathrm{p} / \mathrm{sh}}}] \text {, }
\end{aligned}
$$

with

$$
\begin{aligned}
l_{\mathrm{sa} / \mathrm{pl}}= & \left(1-\eta_{\mathrm{sa} / \mathrm{pl}}\right) H^{+}(\Delta \omega), \\
l_{\mathrm{ax} / \mathrm{sa}}= & \mu_{\mathrm{ax} / \mathrm{sa}} \frac{d_{\mathrm{ax}}}{4 R_{\mathrm{s}}} \frac{\Delta \omega}{\omega_{\mathrm{rg}}} \\
l_{\mathrm{sa} / \mathrm{sh}}= & \mu_{\mathrm{sh}} \frac{R_{\mathrm{sa}}}{2 R_{\mathrm{s}}} \tan \alpha \sin \delta \\
& \times\left(\frac{\cos \left(\delta_{1}+\delta_{0}\right) \sin \left(\delta_{1}-\delta_{0}\right)-\left(\delta_{1}-\delta_{0}\right)}{\sin \left(\delta_{0}+\delta_{1}\right) \sin \left(\delta_{0}-\delta_{1}\right)}\right) \frac{\Delta \omega}{\omega_{\mathrm{rg}}} \\
l_{\mathrm{pl} / \mathrm{sh}}= & \left.\mu_{\mathrm{sh}} \frac{R_{\mathrm{sa}} \tan \alpha \cos \delta}{2 R_{p}}\right) \frac{\Delta \omega}{\omega_{\mathrm{rg}}} \\
& \times\left(\frac{\cos \left(\delta_{2}+\delta_{0}^{\prime}\right) \sin \left(\delta_{2}-\delta_{0}^{\prime}\right)-\left(\delta_{2}-\delta_{0}^{\prime}\right)}{\sin \left(\delta_{0}^{\prime}+\delta_{2}\right) \sin \left(\delta_{0}^{\prime}-\delta_{2}\right)}\right.
\end{aligned}
$$

where $l_{i}=P_{i} / P_{\text {rg }}$ denotes the loss ratio of the $i$-mechanism (with $i=(\mathrm{sa} / \mathrm{pl}, \mathrm{ax} / \mathrm{sa}, \mathrm{sa} / \mathrm{sh}, \mathrm{pl} / \mathrm{sh})$ ). It is worth noting that the differential yield, $\eta_{\text {di }}$, shows mechanical friction losses whenever the rotational-speed differs between two of the planetary pinions associated with the driven wheels, that is, when $\Delta \omega>0$.

\section{Discussions}

In the first part of this section, we discuss the order of magnitude of the constitutive parameters of the model presented in Section 2 . In the second part, we present a sensitivity analysis 


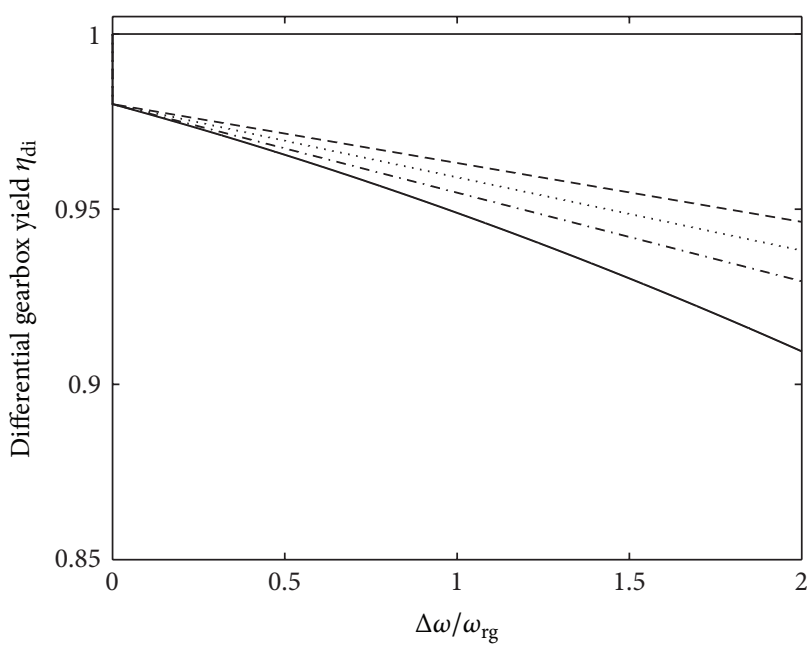

(a)

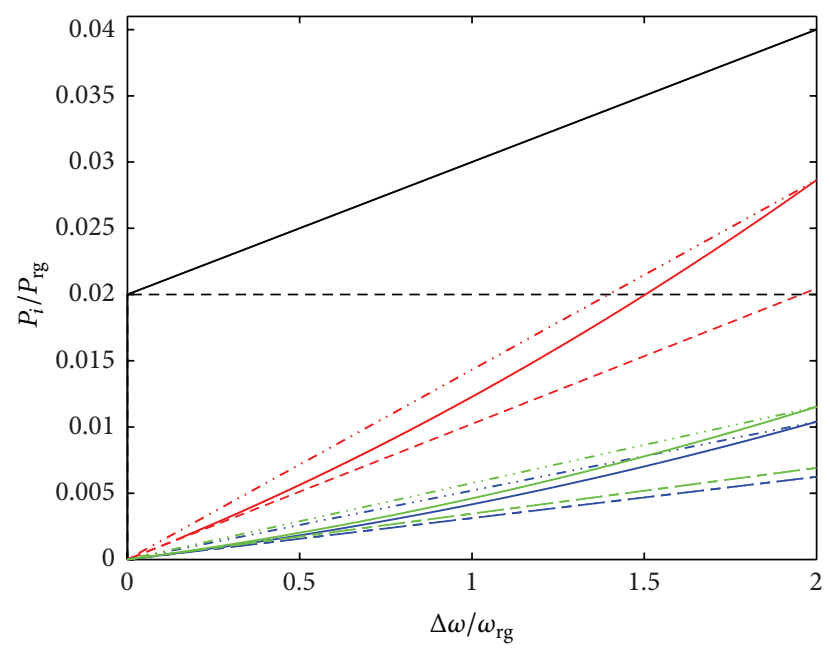

(b)

FigURE 10: (a) Yield of a differential gearbox $\eta_{\mathrm{di}}$ as a function of the load parameter $\Delta \omega / \omega_{\mathrm{rg}}$ for various sets of coefficients of friction $\left(\mu_{\mathrm{ax} / \mathrm{sa}}, \mu_{\mathrm{sh}}\right)$ : $(0.03,0.05)$ in a dashed line, $(0.05,0.07)$ in a dash-dot line, $(0.03,0.07)$ in a dotted line and in a solid line for $\left(\mu_{\mathrm{ax} / \mathrm{sa}}, \mu_{\mathrm{sh}}\right)$, and $\eta_{\mathrm{sa} / \mathrm{pl}}$ undergoing a concomitant linear increase from $(0.03,0.05)$ to $(0.05,0.07)$ and 0.98 to 0.96 , respectively, with $\Delta \omega / \omega_{\mathrm{rg}}$; the thick solid line gives the yield of the differential gearbox without any losses (which is constant) with the load parameter $\Delta \omega / \omega_{\mathrm{rg}}$; that is, $l_{i}=P_{i} / P_{\mathrm{rg}}=0, \forall i$. (b) Loss ratio $l_{i}=P_{i} / P_{\mathrm{rg}}$ of the $i$-mechanism (with $i=(\mathrm{sa} / \mathrm{pl}, \mathrm{ax} / \mathrm{sa}, \mathrm{sa} / \mathrm{sh}, \mathrm{pl} / \mathrm{sh})$ ) as a function of the load parameter $\Delta \omega / \omega_{\mathrm{rg}}$ and with the same sets of coefficients of friction as in (a): $l_{\mathrm{sa} / \mathrm{pl}}$ without (black solid line) or with (black dashed line) a linear decrease in $\eta_{\mathrm{sa} / \mathrm{pl}}$ from 0.98 to $0.96, l_{\mathrm{ax} / \mathrm{sa}}$ (red line), $l_{\mathrm{sa} / \mathrm{sh}}$ (blue line), and $l_{\mathrm{pl} / \mathrm{sh}}$ (green line).

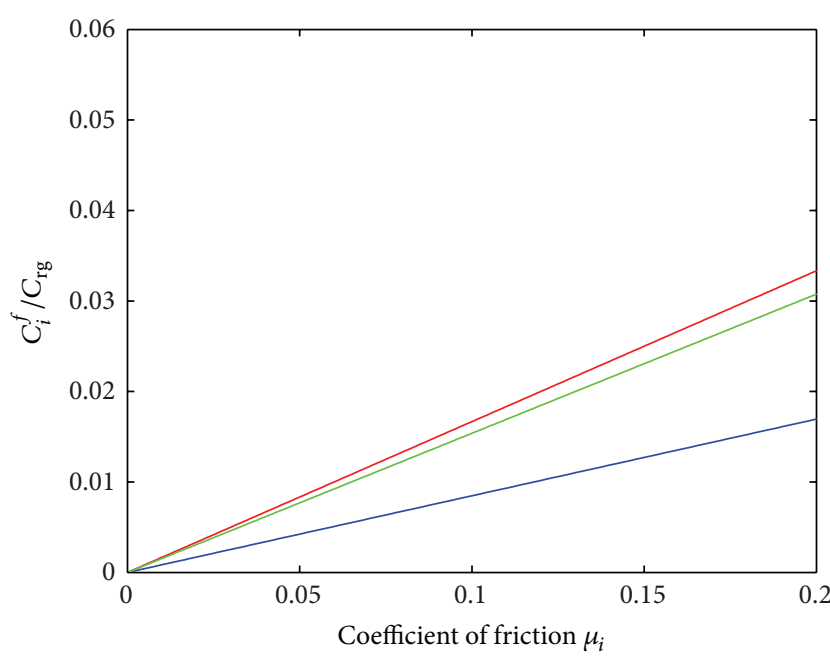

FIGURE 11: Friction torque ratio $C_{i} / C_{\mathrm{rg}}$ as a function of coefficient of friction $\mu_{i}$ with $i=(\mathrm{ax} / \mathrm{sa}, \mathrm{sa} / \mathrm{sh}, \mathrm{pl} / \mathrm{sh}$ ) (while the other parameters were taken to be constant): $C_{\mathrm{ax} / \mathrm{sa}} / C_{\mathrm{rg}}$ increased linearly with $\mu_{\mathrm{ax} / \mathrm{sa}}$ (red solid line), $C_{\mathrm{sa} / \mathrm{sh}} / C_{\mathrm{rg}}$ increased linearly with $\mu_{\mathrm{sa} / \mathrm{sh}}=\mu_{\mathrm{sh}}$ (blue solid line), $C_{\mathrm{pl} / \mathrm{sh}} / C_{\mathrm{rg}}$ increased linearly with $\mu_{\mathrm{pl} / \mathrm{sh}}=\mu_{\mathrm{sh}}$ (green solid line) in a range of variation $\mu_{i} \in[0,0.2]$.

in which the response of the model to a given load parameter was examined in order to assess the effect of this response on the mechanical losses occurring in the differential gearbox mechanism.

3.1. Order of Magnitude of the Constitutive Parameters. This analytical model involves thirteen parameters $\left(\eta_{\mathrm{sa} / \mathrm{pl}}, \mu_{\mathrm{ax} / \mathrm{sa}}\right.$,

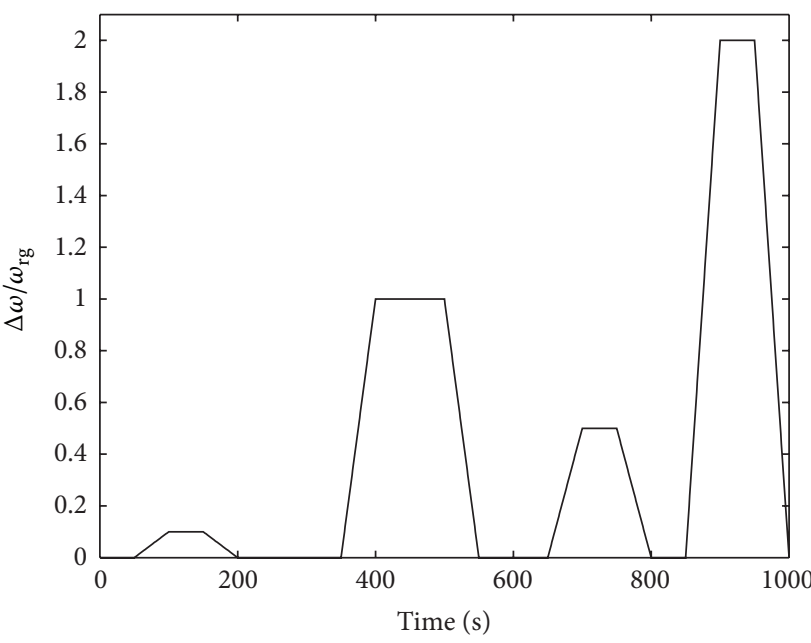

FIGURE 12: Example of a load parameter $\Delta \omega / \omega_{\text {rg }}$ with a complex path depending on time $t \in[0,1000 \mathrm{~s}]$ : when $\Delta \omega / \omega_{\mathrm{rg}}=0$ (in the case where $\omega_{\mathrm{lw}} \neq 0$ and $\omega_{\mathrm{rw}} \neq 0$ ) then $\eta_{\mathrm{di}}=1$ and $l_{i}=P_{i} / P_{\mathrm{rg}}=0, \forall i$ (when the vehicle was travelling along a straight line), when $0<\Delta \omega / \omega_{\mathrm{rg}}<2$ then $\eta_{\mathrm{di}}<1$ and $l_{i}=P_{i} / P_{\mathrm{rg}}>0, \forall i$ (when the vehicle was taking a curvilinear course), when $\Delta \omega / \omega_{\mathrm{rg}}=2$ then $\eta_{\mathrm{di}}<1$ and $l_{i}=P_{i} / P_{\mathrm{rg}}>$ $0, \forall i$ (when one of the driven wheels underwent slipping, the vehicle was stationary); on the plateau, $\Delta \omega / \omega_{\mathrm{rg}}=$ constant and $\left|\omega_{\mathrm{lw}}-\omega_{\mathrm{rw}}\right|=$ constant (the vehicle was taking a constant curvilinear trajectory).

$\left.\mu_{\mathrm{sh}}, d_{\mathrm{ax}}, R_{s}, R_{p}, R_{\mathrm{sa}}, \alpha, \delta, \delta_{0}, \delta_{0}^{\prime}, \delta_{1}, \delta_{2}\right)$ consisting of (i) ten geometrical parameters $\left(d_{\mathrm{ax}}, R_{s}, R_{\mathrm{p}}, R_{\mathrm{sa}}, \alpha, \delta, \delta_{0}, \delta_{0}^{\prime}, \delta_{1}, \delta_{2}\right)$ depending on the differential gearbox under consideration, 


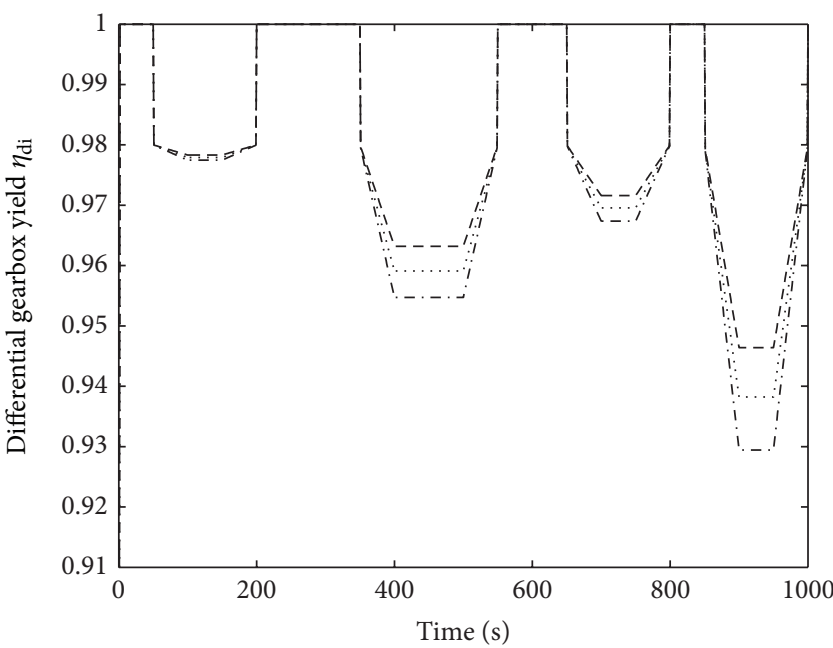

(a)

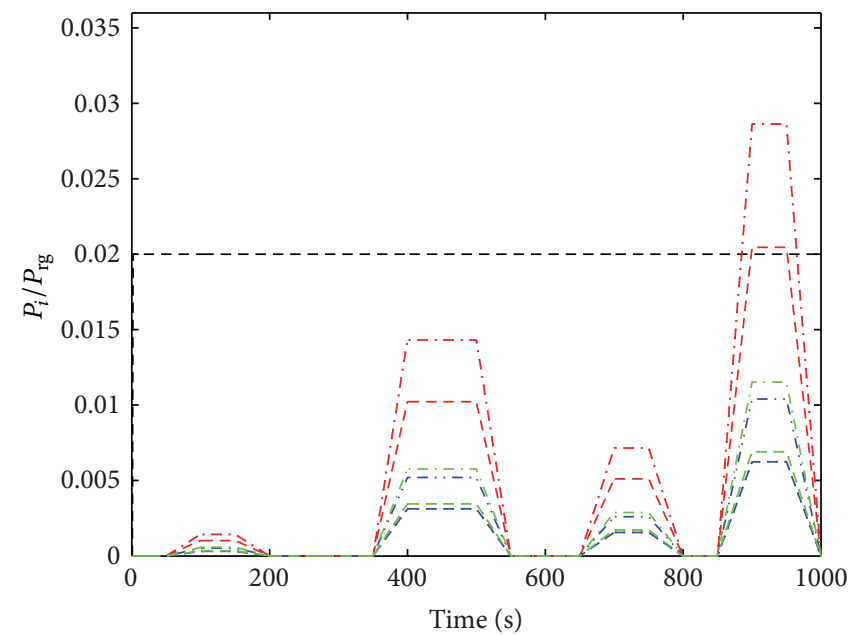

(b)

FIGURE 13: (a) Yield of a differential gearbox $\eta_{d i}$ with time $t \in[0,1000 \mathrm{~s}]$ in the case of the complex path presented in Figure 12 with various sets of friction coefficients $\left(\mu_{\mathrm{ax} / \mathrm{sa}}, \mu_{\mathrm{sh}}\right):(0.03,0.05)$ in a dashed line, $(0.05,0.07)$ in a dash-dot line, and $(0.03,0.07)$ in a dotted line. (b) Loss ratio $l_{i}=P_{i} / P_{\mathrm{rg}}$ of the $i$-mechanism (with $i=(\mathrm{sa} / \mathrm{pl}, \mathrm{ax} / \mathrm{sa}, \mathrm{sa} / \mathrm{sh}, \mathrm{pl} / \mathrm{sh})$ ) with time $t \in[0,1000 \mathrm{~s}]$ in the case of the complex path presented in Figure 12 with the same sets of friction coefficients as in (a): $l_{\mathrm{sa} / \mathrm{pl}}=0.96$ which remained constant with time $t$ (black solid line), $l_{\mathrm{ax} / \mathrm{sa}}(\mathrm{red}$ line), $l_{\mathrm{sa} / \mathrm{sh}}$ (blue line), and $l_{\mathrm{pl} / \mathrm{sh}}$ (green line).

which can be identified fairly easily; (ii) one yield parameter $\left(\eta_{\mathrm{sa} / \mathrm{pl}}\right)$ corresponding to the power transmitted by the gear between the satellite/planetary pinions; (iii) two friction parameters $\left(\mu_{\mathrm{ax} / \mathrm{sa}}, \mu_{\mathrm{sh}}\right)$ which depend considerably on the types of materials in contact and the surface conditions, their state of lubrication, and their temperature.

Concerning (i), although these specific parameters depend on the differential gearbox under consideration, their order of magnitude can be said to be $d_{\mathrm{ax}} \approx 10-20 \mathrm{~mm}, R_{\mathrm{s}} \approx$ 20-30 mm, $R_{p} \approx 20-30 \mathrm{~mm}, R_{\mathrm{sa}} \approx 30-50 \mathrm{~mm}$, and for the angle parameters: $\delta_{0} \approx 10^{\circ}-15^{\circ}, \delta_{0}^{\prime} \approx 15^{\circ}-25^{\circ}, \delta_{1} \approx 30^{\circ}-40^{\circ}$, $\delta_{2} \approx 35^{\circ}-45^{\circ}, \alpha \approx 20-25^{\circ}, \delta \approx 30^{\circ}-40^{\circ}$; readers can refer to Fanchon [19] for further details about some of them.

Concerning (ii), the parameter $\eta_{\mathrm{sa} / \mathrm{p}}$, which denotes the power transmitted by the gear between satellite/planetary pinions using a yield term, has a value ranging between 0.92 and 0.98. Since Fanchon [19] has reported that the yield in the case of two meshed pinions is around 98\%, it can be concluded that in a differential mechanism, where there are four pinions in contact, the lowest value of $\eta_{\mathrm{sa} / \mathrm{pl}} \approx(0.98)^{4} \cong$ 0.92 and the highest value is likely to be $\eta_{\mathrm{sa} / \mathrm{pl}} \cong 0.98$. It therefore seems reasonable to assume that the real yield $\eta_{\mathrm{sa} / \mathrm{pl}}$ of this complex mechanism is approximately 0.96 .

The parameters that need to be investigated more closely in order to determine their influence on the mechanical losses are the various coefficients of friction (iii): $\mu_{\mathrm{ax} / \mathrm{sa}}$ and $\mu_{\mathrm{sh}}$. The sliding contacts in the differential gearbox mechanism can be of very different kinds [20, 21], since both the satellite/planetary bevel pinion and satellite-pinion/satellitecarrier axis in contact are in the mixed elastohydrodynamic lubrication (MEHL) mode [22-24], which is a mixed regime between (1) elastohydrodynamic lubrication (EHL) $[25,26]$, where the heavy loads exerted at the surface of the two gears (due to the presence of both high contact pressures and strong transmitted torques) induce elastic strains in the two solids in contact with thin lubricant films, and (2) boundary lubrication (BL) [27], which may tend to constitute a completely dry frictional contact [28], leading to the development of scuffing effects $[29,30]$. The contacts between the bevel head pinion (satellites and planetaries) and the plastic shell are in the elastohydrodynamic lubrication mode (EHL) which can lead to the development of the hydrodynamic lubrication regime (HL) [31, 32], where the lubricant film thickness is large enough to completely separate the directly apposed surfaces so that the loads applied between the surfaces are restored and balanced under specific operating conditions. Under the above conditions, the contacts existing between the satellite pinions and the satellite-carrier axis are of the steel/steel contact with lubrication type, $\mu_{\mathrm{ax} / \mathrm{sa}} \in[0.05,0.07]$, and those existing between the head pinions and the plastic shell are rather of the steel/Teflon contact with lubrication type, $\mu_{\mathrm{sh}} \in[0.03,0.05]$.

\subsection{Sensitivity Analysis: Assessment of the Model's Response} to a Given Load Parameter and Prediction of the Mechanical Losses. In what follows, it is proposed to test the model's response to a given load parameter and to determine the influence of some parameters $\left(\eta_{\mathrm{sa} / \mathrm{p}}, \mu_{\mathrm{ax} / \mathrm{sa}}, \mu_{\mathrm{sh}}\right)$ on the mechanical losses occurring in a differential gearbox mechanism. The expression for the load parameter $\Delta \omega / \omega_{\mathrm{rg}} \in[0,2]$ means that (i) when $\Delta \omega / \omega_{\mathrm{rg}}=0$ (in cases where $\omega_{\mathrm{lw}} \neq 0$ and $\left.\omega_{\mathrm{rw}} \neq 0\right)$, the vehicle is travelling on a straight line: $\eta_{\mathrm{di}}=1$ and $l_{i}=P_{i} / P_{\mathrm{rg}}=0, \forall i$; (ii) when $0<\Delta \omega / \omega_{\mathrm{rg}}<2$, the vehicle is taking a curvilinear course: $\eta_{\mathrm{di}}<1$ and $l_{i}=P_{i} / P_{\mathrm{rg}}>0, \forall i$; (iii) when $\Delta \omega / \omega_{\mathrm{rg}}=2$, one of the driven wheels undergoes 
slipping (the extreme situation), the vehicle is stationary: $\eta_{\mathrm{di}}<1$ and $l_{i}=P_{i} / P_{\mathrm{rg}}>0, \forall i$.

The values adopted for the other parameters are $d_{\mathrm{ax}}=$ $18 \times 10^{-3} \mathrm{~m}, R_{s}=22 \times 10^{-3} \mathrm{~m}, R_{p}=27 \times 10^{-3} \mathrm{~m}, R_{\mathrm{sa}}=$ $49 \times 10^{-3} \mathrm{~m}, \delta_{0}=10^{\circ}, \delta_{0}^{\prime}=18^{\circ}, \delta_{1}=32^{\circ}, \delta_{2}=40^{\circ}, \alpha=20^{\circ}$, $\delta=39^{\circ}$.

Figure 10(a) shows the yield of a differential gearbox $\eta_{\mathrm{di}}$ depending on the load parameter $\Delta \omega / \omega_{\text {rg }}$ with various sets of friction coefficients of friction $\left(\mu_{\mathrm{ax} / \mathrm{sa}}, \mu_{\mathrm{sh}}\right)$ and a linear decrease in $\eta_{\mathrm{sa} / \mathrm{pl}}$ from 0.98 to 0.96 . In the most gentle operating range, that is, $0 \leq \Delta \omega / \omega_{\mathrm{rg}} \leq 1, \eta_{\mathrm{di}}$ decreased from 0.98 to around $0.963,\left(\mu_{\mathrm{ax} / \mathrm{sa}}, \mu_{\mathrm{sh}}\right)=(0.03,0.05), \eta_{\mathrm{di}} \in[0.98,0.959]$ (resp., $\left.\eta_{\mathrm{di}} \in[0.98,0.954]\right)$ when $\left(\mu_{\mathrm{ax} / \mathrm{sa}}, \mu_{\mathrm{sh}}\right)=(0.03,0.05)$ (resp., $\left.\left(\mu_{\mathrm{ax} / \mathrm{sa}}, \mu_{\mathrm{sh}}\right)=(0.05,0.07)\right)$ and $\eta_{\mathrm{di}}$ decrease from 0.98 to around 0.949 when $\left(\mu_{\mathrm{ax} / \mathrm{sa}}, \mu_{\mathrm{sh}}\right)$ showed a concomitant linear increase from $(0.03,0.05)$ to $(0.05,0.07)$. In the heavy operating range, that is, $1<\Delta \omega / \omega_{\text {rg }} \leq 2$, the maximum differential gearbox yield $\left.\left.\eta_{\mathrm{di}} \in\right] 0.963,0.946\right]$ was obtained with $\left(\mu_{\mathrm{ax} / \mathrm{sa}}, \mu_{\mathrm{sh}}\right)=(0.03,0.05)$, and the minimum yield $\left.\left.\left(\eta_{\mathrm{di}} \in\right] 0.949,0.909\right]\right)$ occurred when $\left(\mu_{\mathrm{ax} / \mathrm{sa}}, \mu_{\mathrm{sh}}\right)$ and $\eta_{\mathrm{sa} / \mathrm{pl}}$ increased linearly from $(0.03,0.05)$ to $(0.05,0.07)$ concomitantly with the load parameter $\left.\left.\Delta \omega / \omega_{\mathrm{rg}} \eta_{\mathrm{di}} \in\right] 0.959,0.938\right]$ (resp., $\left.\left.\left.\eta_{\mathrm{di}} \in\right] 0.954,0.929\right]\right)$ when $\left(\mu_{\mathrm{ax} / \mathrm{sa}}, \mu_{\mathrm{sh}}\right)=(0.03,0.05)$ (resp., $\left.\left(\mu_{\mathrm{ax} / \mathrm{sa}}, \mu_{\mathrm{sh}}\right)=(0.05,0.07)\right)$. The results presented in Figure 10(b) show the loss ratio $l_{i}=P_{i} / P_{\text {rg }}$ associated with $i$-mechanism (where $i=(\mathrm{sa} / \mathrm{pl}, \mathrm{ax} / \mathrm{sa}, \mathrm{sa} / \mathrm{sh}, \mathrm{pl} / \mathrm{sh})$ ) in decreasing order of influence: $l_{\mathrm{ax} / \mathrm{sa}}$ (red line), $l_{\mathrm{sa} / \mathrm{pl}}$ (black line), $l_{\mathrm{pl} / \mathrm{sh}}$ (green line), $l_{\mathrm{sa} / \mathrm{sh}}$ (blue line) when $\eta_{\mathrm{sa} / \mathrm{pl}}$ had a constant value of 0.98 , and in the case where $\eta_{\mathrm{sa} / \mathrm{pl}}$ decreased from 0.98 to 0.96 , the effects of the loss ratio $l_{\mathrm{sa} / \mathrm{pl}}$ became greater than those of the other parameters $\left(l_{\mathrm{ax} / \mathrm{sa}}, l_{\mathrm{ax} / \mathrm{sa}}, l_{\mathrm{sa} / \mathrm{sh}}, l_{\mathrm{pl} / \mathrm{sh}}\right)$. It should be noted that when $0 \leq \Delta \omega / \omega_{\text {rg }} \leq 1$, then $l_{\mathrm{ax} / \mathrm{sa}} \in[0,0.0143], l_{\mathrm{pl} / \mathrm{sh}} \in[0,0.0057]$, and $l_{\mathrm{sa} / \mathrm{sh}} \in[0,0.0052]$, whereas when $1<\Delta \omega / \omega_{\mathrm{rg}} \leq 2$, then $l_{\mathrm{ax} / \mathrm{sa}} \in[0,0.0286]$, $l_{\mathrm{pl} / \mathrm{sh}} \in[0,0.0115]$, and $l_{\mathrm{sa} / \mathrm{sh}} \in[0,0.0104]$. Figure 11 shows the friction torque ratio $C_{i} / C_{\mathrm{rg}}$ as a function of the friction coefficient $\mu_{i}$ with $i=(\mathrm{ax} / \mathrm{sa}, \mathrm{sa} / \mathrm{sh}, \mathrm{pl} / \mathrm{sh})$ when the other parameters were taken to be fixed constants. The range of variation of the friction coefficient $\mu_{i}$ was taken to be between 0 and 0.2 (this extreme value may correspond to steel/steel contact without any lubrification). In view of these results, the maximum $C_{i} / C_{\mathrm{rg}}$ ratio was obtained with $C_{\mathrm{ax} / \mathrm{sa}} / C_{\mathrm{rg}}$ and the minimum one with $C_{\mathrm{sa} / \mathrm{sh}} / C_{\mathrm{rg}}$. The friction torque ratios $C_{i} / C_{\mathrm{rg}}$ progressed linearly with the friction coefficient $\mu_{i}$ (where $\mu_{\mathrm{sh}}=\mu_{\mathrm{sa} / \mathrm{sh}}=\mu_{\mathrm{pl} / \mathrm{sh}}$ ), as predicted by the constitutive equations in Section 2. Note that the results obtained in this first approximation are likely to differ from those obtained by simulating nonlinear behaviour between $C_{i} / C_{\mathrm{rg}}$ and $\mu_{i}$.

A complex path of the load parameter $\Delta \omega / \omega_{\text {rg }}$ was then studied in order to test the ability of the model to describe the differential gearbox yield, $\eta_{\text {di }}$, and the loss ratios $l_{i}=P_{i} / P_{\mathrm{rg}}$ associated with the $i$-mechanism (where $i=$ (sa/pl, ax/sa, sa/sh, pl/sh)) under more realistic conditions involving a straight line situation $\left(\Delta \omega / \omega_{\mathrm{rg}}=0\right.$ with $\omega_{\mathrm{lw}} \neq 0$ and $\left.\omega_{\text {rw }} \neq 0\right)$, a curved line situation $\left(0<\Delta \omega / \omega_{\text {rg }}<2\right)$, a constant curved line situation $\left(\Delta \omega / \omega_{\mathrm{rg}}=\right.$ constant $)$ or where one of the driven wheels undergoes slipping $\left(\Delta \omega / \omega_{\text {rg }}=\right.$ 2 ). Figure 12 shows the evolution of the load parameter
$\Delta \omega / \omega_{\mathrm{rg}}$ as a function of the time $t \in[0,1000 \mathrm{~s}]$. The results obtained with a complex path in terms of the yield of the differential gearbox $\left(\eta_{\mathrm{di}}\right)$ and the loss ratios $\left(l_{i}\right)$ are shown in Figure 13. Specifically, Figure 13(a) gives the yield of the differential gearbox, $\eta_{\mathrm{di}}$, as a function of the time $t \in[0,1000 \mathrm{~s}]$ in the case of the complex path plotted in Figure 12 with various sets of friction coefficients $\left(\mu_{\mathrm{ax} / \mathrm{sa}}, \mu_{\mathrm{sh}}\right)$ : $(0.03,0.05)$ in dashed line, $(0.05,0.07)$ in dash-dot line, and $(0.03,0.07)$ in dotted line. During the whole complex path of $\Delta \omega / \omega_{\mathrm{rg}}$, the maximum (resp., minimum) yield of differential gearbox was reached with $\mu_{\mathrm{ax} / \mathrm{sa}}=0.03$ and $\mu_{\mathrm{sh}}=0.05$ (resp., $\mu_{\mathrm{ax} / \mathrm{sa}}=0.05$ and $\mu_{\mathrm{sh}}=0.07$ ). On the $k$-plate (with $k=1,2,3,4)$ defined by the $k$-time interval $\left[t^{i}, t^{f}\right]_{k}$, it can be noted that, for example (1) in $[400 \mathrm{~s}, 500 \mathrm{~s}]_{2}, \eta_{\mathrm{di}} \approx 0.9774$ with $(0.05,0.07), \eta_{\mathrm{di}} \approx 0.9591$ with $(0.03,0.07)$, and $\eta_{\mathrm{di}} \approx 0.9547$ with $(0.05,0.07) ;(2)$ in $[900 \mathrm{~s}, 950 \mathrm{~s}]_{4}, \eta_{\mathrm{di}} \approx 0.9464$ with $(0.05,0.07), \eta_{\mathrm{di}} \approx 0.9382$ with $(0.03,0.07)$, and $\eta_{\mathrm{di}} \approx 0.9294$ with $(0.05,0.07)$. The loss ratios due to friction $l_{i}=P_{i} / P_{\mathrm{rg}}$ are shown in Figure 13(b). The maximum loss ratios obtained in decreasing order of magnitude (along the loading path) were $l_{\mathrm{sa} / \mathrm{pl}}$ (black line), $l_{\mathrm{ax} / \mathrm{sa}}$ (red line), $l_{\mathrm{pl} / \mathrm{sh}}$ (green line), and $l_{\mathrm{sa} / \mathrm{sh}}$ (blue line), except for the last load where $l_{\mathrm{ax} / \mathrm{sa}}$ could be greater than $l_{\mathrm{sa} / \mathrm{pl}}$ with the pair of friction coefficients $(0.05,0.07)$ and $(0.03,0.07)$. It should be noted that (1) on the second plate $\left([400 \mathrm{~s}, 500 \mathrm{~s}]_{2}\right), l_{\mathrm{ax} / \mathrm{sa}}^{\mathrm{max}} \approx 0.0143$ with $(0.05,0.07), l_{\mathrm{pl} / \mathrm{sh}}^{\mathrm{max}} \approx$ 0.0057 with $(0.03,0.07)$, and $\eta_{\mathrm{di}} \approx 0.0052$ with $(0.05,0.07)$; (2) on the fourth plate $\left([900 \mathrm{~s}, 950 \mathrm{~s}]_{4}\right), l_{\mathrm{ax} / \mathrm{sa}}^{\mathrm{max}} \approx 0.0286$ with $(0.05,0.07), l_{\mathrm{pl} / \mathrm{sh}}^{\max } \approx 0.0115$ with $(0.03,0.07)$, and $\eta_{\mathrm{di}} \approx 0.0104$ with $(0.05,0.07)$.

Although only a sensitivity analysis was performed on the model, the results obtained show quite clearly that this model can be used to assess and predict the mechanical friction losses occurring in a differential gearbox. An experimental study shall be conducted in order to obtain more realistic values for some of the parameters, such as the friction coefficients $\left(\mu_{\mathrm{ax} / \mathrm{sa}}\right.$ and $\left.\mu_{\mathrm{sh}}\right)$, which significantly influence both the friction torques and the differential gearbox yield.

\section{Conclusion}

In this paper, an analytical model is presented for assessing and predicting the mechanical friction losses occurring in differential gearboxes. Some of the parameters involved in this model can be determined quite easily (geometric parameters), while others, which are more delicate, depend directly on the type of friction occurring in the mechanism (and therefore on the friction coefficients), which affects the mechanical losses to a variable extent. In order to test the influence of these parameters and determine the ability of the model to predict any mechanical losses, a sensitivity analysis was conducted. After this initial numerical approach, an experimental study shall be performed in order to obtain more realistic values for some of the parameters and confirm some of the assumptions made here in the modelling procedure. 


\section{Conflict of Interests}

The author declares that there is no conflict of interests regarding the publication of this paper.

\section{Acknowledgments}

The author is greatly indebted to Dr. J.-L. Ligier for helpful discussions, comments, and advices. The author would like to thank also Dr. Jessica Blanc for her help with this paper.

\section{References}

[1] S. C. Lee and H. S. Cheng, "Scuffing theory modeling and experimental correlations," Journal of Tribology, vol. 113, no. 2, pp. 327-334, 1991.

[2] D. Dowson, G. Dalmaz, Childs, M. T. H. C. Godet, and C. M. Taylor, Thin Films in Tribology, Elsevier Science, 1993.

[3] J. C. Enthoven, P. M. Cann, and H. A. Spikes, "Temperature and scuffing," Tribology Transactions, vol. 36, no. 2, pp. 258-266, 1993.

[4] D. Dowson, G. Dalmaz, T. H. C. Childs, and C. M. Taylor, Lubricants and Lubrication, Elsevier Science, 1995.

[5] C. Taylor, L. Flamand, G. Dalmaz et al., Elastohydrodynamics'96: Fundamentals and Applications in Lubrication and Traction, Elsevier Science, 1997.

[6] M. Priest, P. Ehret, L. Flamand et al., Lubrication at the Frontier: the Role of the Interface and Surface Layers in the Thin Film and Boundary Regime, Elsevier Science, 1999.

[7] A. Cornet and J. P. Deville, Physique et Ingénierie des Surfaces, EDP Sciences, 1998.

[8] W. Piekoszewski, M. Szczerek, and W. Tuszynski, "The action of lubricants under extreme pressure conditions in a modified," Wear, vol. 249, no. 3-4, pp. 188-193, 2001.

[9] M. Wisniewski, M. Szczerek, and W. Tuszynski, "The temperatures at scuffing and seizure in a four-ball contact," Lubrication Science, vol. 16, no. 3, pp. 215-227, 2004.

[10] Q. Wang, "Seizure failure of journal-bearing conformal contacts," Wear, vol. 210, no. 1-2, pp. 8-16, 1997.

[11] G. Spinnler, Conception Des Machines-Principes Et Applications, vol. 1, Presses Polytechniques et Universitaires Romandes, 2002.

[12] L. Flamand, Fatigue Des Surface, Techniques De L'Ingénieur, 1993.

[13] J. L. Ligier, Matériaux Pour Palier Lisses, Techniques De L'Ingénieur, 1995.

[14] J. L. Ligier, Avaries En Lubrification, Ecole Nationales Supérieure Du Pétrole Et Des Moteurs, Editions Technip, 2007.

[15] M. Aublin, R. Boncompain, M. Boulaton et al., Systémes Mécaniques-Théorie Et Dimensionnement, Dunod, 2005.

[16] J. L. Ligier and R. Gojon, "Prédiction de l'usure et du grippage d'un palier de moteur diesel," Tech. Rep. SIA 93065, 1993.

[17] J. L. Ligier, Lubrification des Paliers Moteurs, Ecole Nationales Supérieure du Pétrole et des Moteurs, Editions Technip, 1997.

[18] S. Picard, Fonctionnement et Maintenance Du VéhiculeTransmission \& Freinage, Delta Press, 1994.

[19] J. L. Fanchon, Guide des Sciences et Technologies Industrielles, Nathan, 2001.
[20] J. H. Mathieu, E. Bergmann, and R. Gras, Analyse et Technologie des Surfaces: Couches Minces et Tribologie, Presses Polytechniques et Universitaires Romandes, Traité des Matériaux, Tome, 2003.

[21] V. N. Constantinescu, Laminar Viscous Flow, Mechanical Engineering Series, Springer, 1995.

[22] Y. Zhang, "Analytical solution to a mode of mixed elastohydrodynamic lubrication with mixed contact regimes: part I. Without consideration of contact adhering layer in the inlet zone," Journal of Molecular Liquids, vol. 130, no. 1-3, pp. 88-94, 2007.

[23] Y. Zhang, "Analytical solution to a mode of mixed elastohydrodynamic lubrication with mixed contact regimes: part IIConsidering the contact adhering layer effect in the inlet zone," Journal of Molecular Liquids, vol. 130, no. 1-3, pp. 95-103, 2007.

[24] S. Li and A. Kahraman, "A fatigue model for contacts under mixed elastohydrodynamic lubrication condition," International Journal of Fatigue, vol. 33, no. 3, pp. 427-436, 2011.

[25] K. L. Johnson, J. A. Greenwood, and S. Y. Poon, "A simple theory of asperity contact in elastohydro-dynamic lubrication," Wear, vol. 19, no. 1, pp. 91-108, 1972.

[26] G. Ramsey, Elastohydrodynamics, Imperial College Press, 2001.

[27] B. J. Hamrock, S. R. Schmid, and B. O. Jacobson, Fundamentals of Fluid Film Lubrication, CRC Press, 2004.

[28] K. L. Johnson, Contact Mechanics, Cambridge University Press, 1987.

[29] R. Brun, Manuel Du Mécanicien et Du Thermicien, Editions Technip, 2000.

[30] P. Arquès, Diagnostic Prédictif et Défaillances Des Machines: Théorie, Traitement, Analyse, Reconnaissance, Prédiction, Editions Technip, 2007.

[31] J. Frêne, D. Nicolas, B. Degueurce, D. Berthe, and M. Godet, Lubrication Hydrodynamique: Paliers Et Butées, Eyrolles, 1990.

[32] J. Frêne, "Butées et paliers hydrodynamique," Tech. Rep. B5055, Techniques de l'Ingénieur, 1995. 

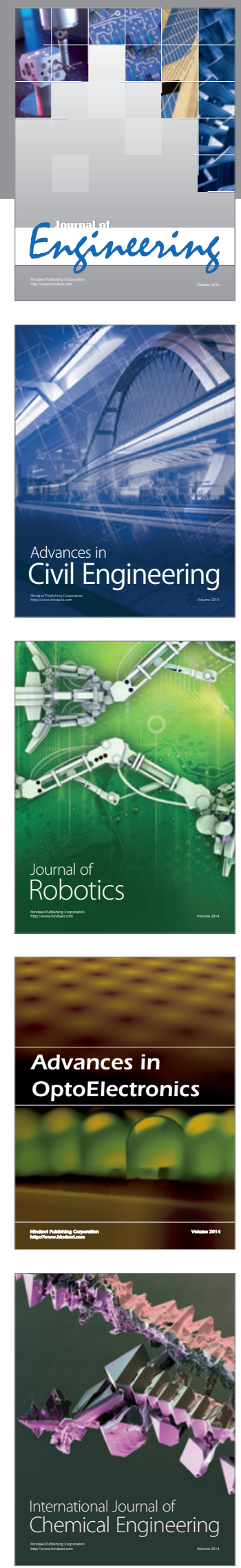

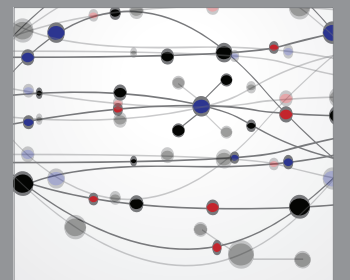

The Scientific World Journal
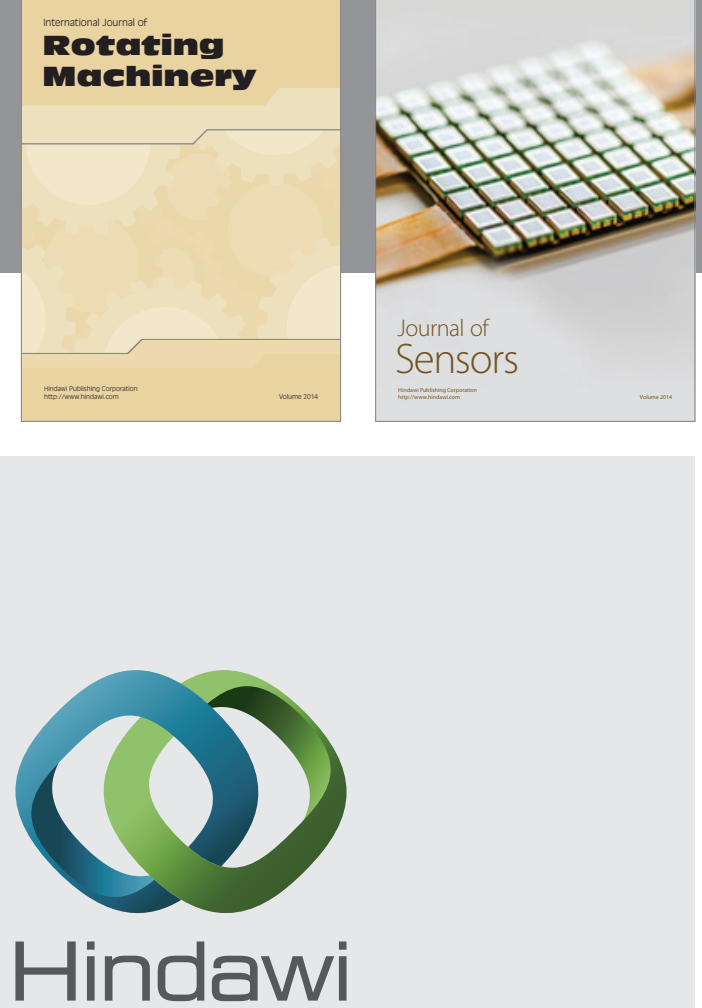

Submit your manuscripts at http://www.hindawi.com
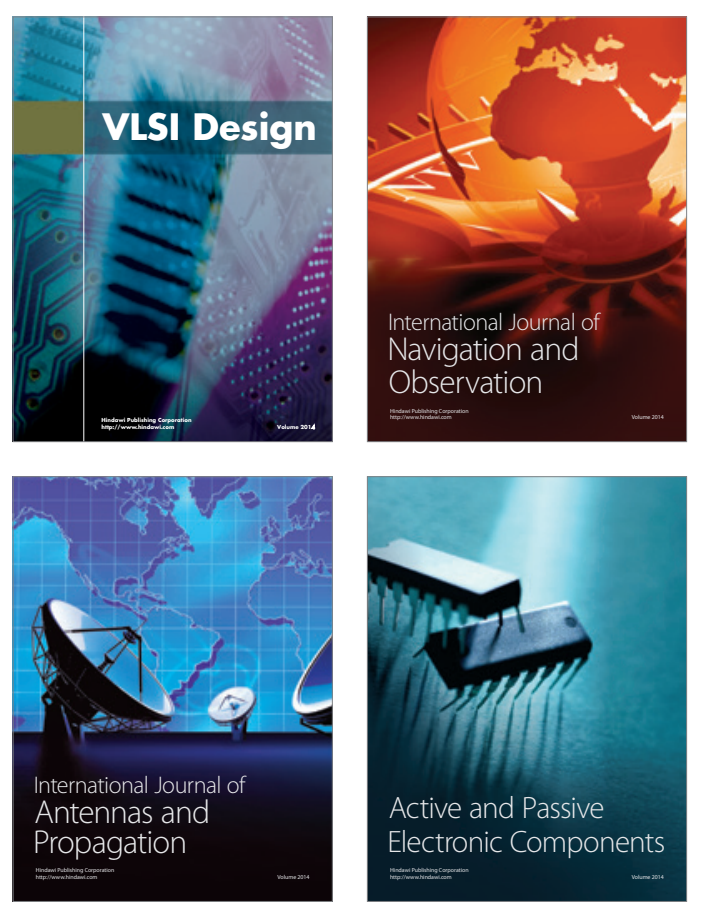
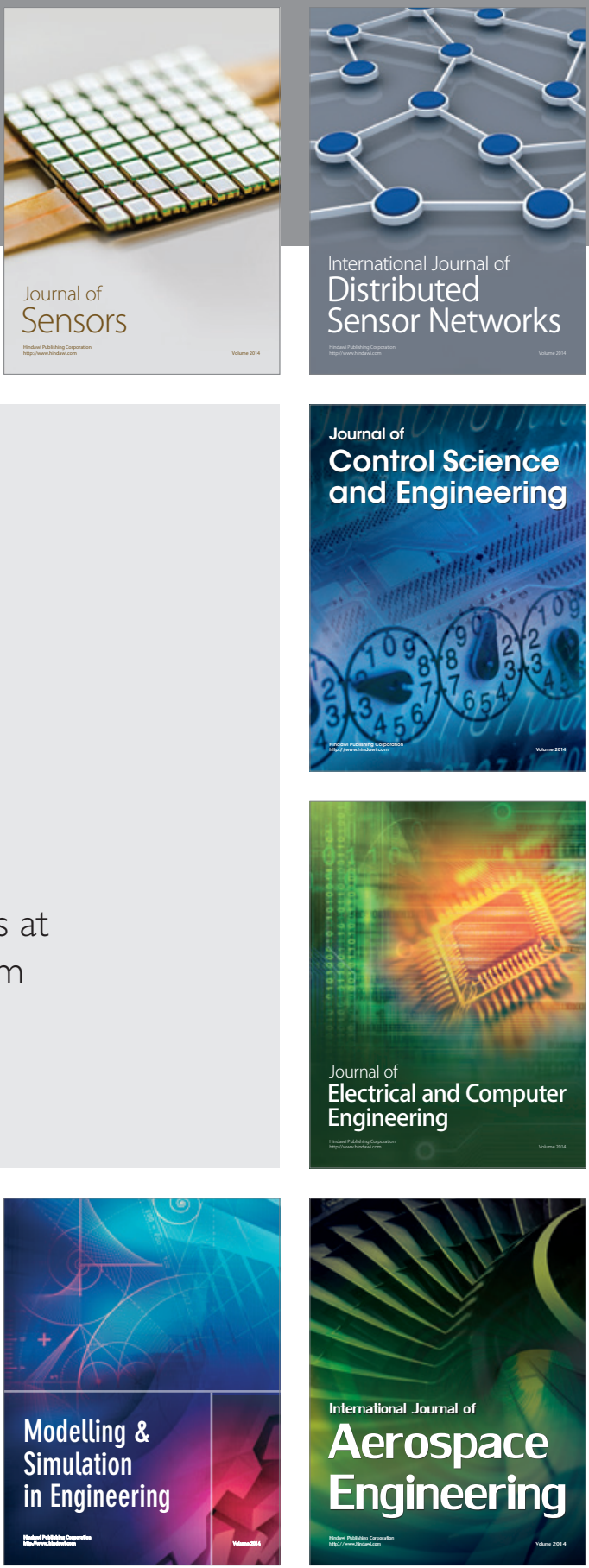

Journal of

Control Science

and Engineering
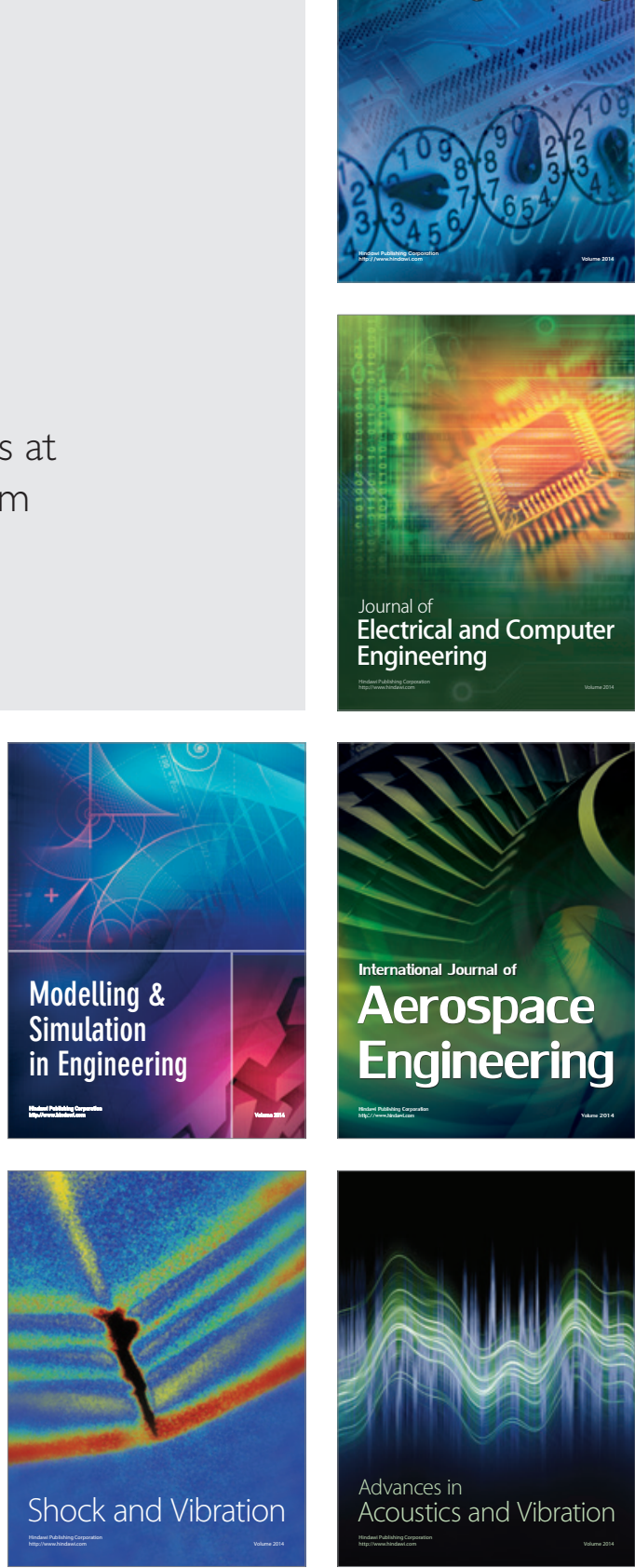